\title{
Aplikasi Pewarnaan Graf pada Penempatan Kamar Mahasiswa (Studi Kasus: Asrama Institut Teknologi Sumatera)
}

\author{
Sri EfrinitaIrwan \\ e-mail: sri.efrinita@ma.itera.ac.id \\ Program StudiMatematika \\ InstitutTeknologi Sumatera
}

\begin{abstract}
This article discusses the application of graph colouring to the placement of students room. The sample data used is the data of prospective students resident ofInstitut Teknologi Sumatera. The graph colouring process in this article utilizes the WelshPowell algorithm and related algebraic theories to facilitate the data processing. The process is carried out to find out the minimum number of rooms needed to place a number of students so that there are no students come from the same study program or UKT group in one room.
\end{abstract}

Keywords: graph, adjacency matrix, Welsh-Powell algorithm

\begin{abstract}
ABSTRAK
Artikel ini membahas aplikasi pewarnaan graf pada penempatan kamar mahasiswa. Sampel data yang digunakan adalah data calon mahasiswa penghuni asrama Institut Teknologi Sumatera. Proses pewarnaan graf pada artikel ini memanfaatkan algoritma Welsh-Powell dan teori aljabar terkait untuk mempermudah proses pengolahan data. Proses tersebut dilakukan untuk mengetahui jumlah minimum kamar yang dibutuhkan untuk menempatkan sejumlah mahasiswa sehingga tidak ada mahasiswa yang berasal dari program studi atau pun golongan UKT yang sama dalam satu kamar.
\end{abstract}

Kata Kunci:graf, matriks ketetanggaan, algoritma Welsh-Powell

\section{PENDAHULUAN}

Institut Teknologi Sumatera merupakan salah satu perguruan tinggi yang menyediakan asrama sebagai salah satu fasilitas bagi mahasiswanya, khususnya mahasiswa tahun pertama. Dalam pengelolaannya, Institut Teknologi Sumatera berupaya menerapkan kebijakan yang bertujuan untuk melatih jiwa sosial di kalangan mahasiswa. Salah satu upaya untuk mencapai hal tersebut adalah dengan menjaga keberagaman mahasiswa yang menempati setiap kamar di asrama. Namun demikian, pengolahan data ratusan mahasiswa calon penghuni asrama untuk memenuhi kriteria yang dimaksudkan dalam kebijakan tersebut bukanlah hal yang mudah untuk dilakukan secara manual.

Sementara itu, dalam cabang ilmu matematika, permasalahan semacam ini biasanya dapat diselesaikan dengan mengaplikasikan teori yang disebut sebagai pewarnaan graf (graph colouring). Pewarnaan graf terbagi menjadi beberapa bagian, diantaranya pewarnaan titik (vertex colouring) dan pewarnaan sisi (edge colouring). 
Berbagai aplikasi pewarnaan graf telah dikemukakan diantaranya dalam Bincy and Presitha (2017), Tosuni (2015), Gupta dan Sikhwal (2014), dan Marx (2004).

Dalam Irwan dan Muliawati (2019), telah dikaji bagaimana teori tentang pewarnaan graf, khususnya pewarnaan titik, dapat digunakan untuk menentukan penempatan kamar mahasiswa di asrama. Sampel data yang digunakan adalah data mahasiswa Institut Teknologi Sumatera. Hal ini bertujuan untuk memudahkan pengolahan data mahasiswa calon penghuni asrama untuk memenuhi kriteria yang dimaksudkan dalam kebijakan-kebijakan yang diberlakukan di lingkungan Institut Teknologi Sumatera. Pada artikel tersebut, pengaturan penempatan kamar mahasiswa dilakukan agar tidak ada mahasiswa yang berasal dari program studi ataupun daerah asal yang sama dalam satu kamar. Namun demikian, hasil yang diperoleh tidak mendukung efektivitas penggunaan kamar asrama. Hal ini disebabkan mayoritas calon mahasiswa penghuni asrama berasal dari propinsi Lampung.

Pada artikel ini, golongan UKT mahasiswa dijadikan indikator pengganti daerah asal dalam pengaturan penempatan kamar mahasiswa. Selain itu, proses pewarnaan graf pada artikel ini akan memanfaatkan teori aljabar terkait untuk mempermudah proses pengolahan data.

$$
\text { Dalam Diestel (2005) }
$$

dikemukakan bahwa graf (graph) adalah suatu pasangan himpunan $G=(V, E)$ sehingga $E \subseteq[V]^{2}$, akibatnya unsurunsur di $E$ merupakan subhimpunansubhimpunan dari $V$ yang terdiri dua unsur di $V$. Unsur-unsur di $V$ adalah titiktitik (vertices) dari graf $G$, sedangkan unsur-unsur di $E$ adalah sisi-sisi (edges) dari graf tersebut.

Himpunan titik-titik dari graf $G$ dinotasikan sebagai $V(G)$, sedangkan himpunan sisi-sisi dari graf $G$ dinotasikan sebagai $E(G)$. Berikut dikemukakan salah satu contoh graf.

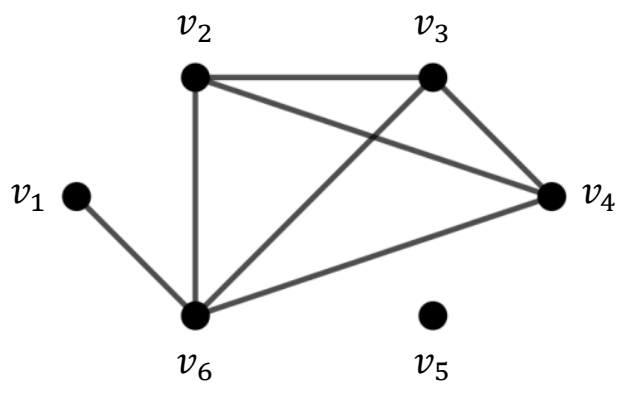

Gambar 1. Graf $H$

Dari gambar tersebut diketahui bahwa $V(H)=\left\{v_{1}, v_{2}, v_{3}, v_{4}, v_{5}, v_{6}\right\}$ dan $E(H)=\left\{e_{1}, e_{2}, e_{3}, e_{4}, e_{5}\right\}$ dengan $e_{1}=\left\{v_{1}, v_{6}\right\}, e_{2}=\left\{v_{2}, v_{3}\right\}, e_{3}=$ $\left\{v_{2}, v_{4}\right\}, e_{4}=\left\{v_{2}, v_{6}\right\}, e_{5}=\left\{v_{3}, v_{4}\right\}, e_{6}=$ $\left\{v_{3}, v_{6}\right\}, e_{7}=\left\{v_{4}, v_{6}\right\}$.

Beberapa istilah berikut merupakan istilah dasar tentang graf yang diperlukan dalam pembahasan selanjutnya.

1. Dua titik $x$ dan $y$ dari graf $G$ dikatakan bertetangga (adjacent) jika $\{x, y\}$ adalah suatu sisi dari graf $G$, yaitu jika titik $x$ dan $y$ dihubungkan oleh suatu sisi dari graf $G$.

2. Suatu sisi $e$ dikatakan bersisian (incident) dengan titik $v_{1}$ dan $v_{2}$ jika $e=\left\{v_{1}, v_{2}\right\}$, yaitu $e$ menghubungkan titik $v_{1}$ dan $v_{2}$.

3. Suatu titik $v$ pada graf $G$ dikatakan memiliki derajat (degree) $n$ jika terdapat $n$ buah sisi yang bersisian dengan $v$. Derajat dari titik $v$ dinotasikan dengan $d(v)$.

Pada graf, dikenal istilah pewarnaan graf (graph colouring). Pewarnaan graf dibedakan menjadi beberapa jenis, diantaranya pewarnaan titik (vertex colouring) dan pewarnaan sisi (edge colouring). Pada artikel ini, 
pewarnaan graf yang dimaksud adalah pewarnaan titik.

Secara formal, suatu pewarnaan titik dari suatu graf $G=(V, E)$ adalah suatu pemetaan $c: V \rightarrow S$ sehingga $c\left(v_{1}\right) \neq c\left(v_{2}\right)$ jika $v_{1}$ bersisian dengan $v_{2}$. Dalam hal ini, $S$ merupakan himpunan yang terdiri dari warna-warna yang tersedia untuk titik-titik pada graf $G$. Informasi penting yang diperlukan dari himpunan $S$ adalah tentang ukuran himpunan itu sendiri. Oleh karena itu, suatu pewarnaan titik $c: V \rightarrow S$ dapat dibatasi menjadi $c: V \rightarrow\{1,2,3, \ldots, k\}$ untuk menyatakan bahwa graf $G$ dapat diwarnai dengan $k$ warna berbeda.

Bilangan bulat positif terkecil $k$ yang memenuhi aturan pewarnaan titik di atas disebut sebagai bilangan kromatik (chromatic number) dari graf $G$ dan dinotasikan sebagai $\chi(G)$. Bilangan kromatik yang dimaksud terkait dengan pewarnaan titik pada graf $G$. Untuk selanjutnya, istilah pewarnaan dalam penelitian ini dikhususkan untuk pewarnaan titik pada graf.

Berikut dikemukakan salah satu contoh pewarnaan graf.

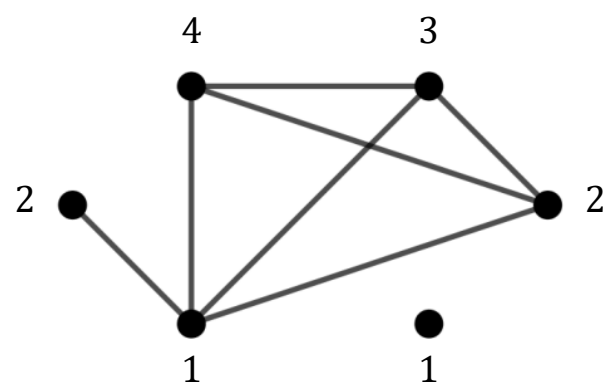

Gambar 2. Graf $H$ dengan pewarnaan $c: V \rightarrow\{1,2,3,4\}$

Dari gambar tersebut, terlihat bahwa graf $H$ yang memiliki enam titik dapat diwarnai dengan empat warna sehingga setiap dua titik yang bersisian memiliki warna yang berbeda.

Proses pewarnaan graf pada artikel ini akan memanfaatkan teori aljabar terkait untuk mempermudah proses pengolahan data, yaitu teori tentang matriks ketetanggaan dari suatu graf. Teori tersebut dijelaskan dalam Biggs (1993) sebagai berikut.

Misalkan $G$ suatu graf dengan $n$ buah titik. Matriks ketetanggaan dari $G$, yang dinotasikan dengan $A=A(G)$, adalah suatu matriks berukuran $n \times n$ dengan entri

$$
a_{i j}=\left\{\begin{array}{l}
1, \text { jika } v_{i} \text { dan } v_{j} \text { bertetangga; } \\
0, \text { lainnya. }
\end{array}\right.
$$

Dengan demikian, jelas bahwa $A$ adalah suatu matriks simetrik. Sebagai contoh, matriks ketetanggaan dari graf $H$ pada Gambar 1 adalah

$$
A(H)=\left[\begin{array}{llllll}
0 & 0 & 0 & 0 & 0 & 1 \\
0 & 0 & 1 & 1 & 0 & 1 \\
0 & 1 & 0 & 1 & 0 & 1 \\
0 & 1 & 1 & 0 & 0 & 1 \\
0 & 0 & 0 & 0 & 0 & 0 \\
1 & 1 & 1 & 1 & 0 & 0
\end{array}\right] .
$$

Matriks ketetanggaan dapat mempermudah proses pewarnaan graf, khususnya untuk graf yang memiliki banyak titik. Jumlah dari entri-entri pada baris (kolom) ke- $i$ menyatakan derajat dari titik $v_{i}$.

Salah satu algoritma yang dapat digunakan dalam proses pewarnaan graf adalah algoritma Welsh-Powell yang dinyatakan sebagai berikut:

1. Tentukan derajat dari masingmasing titik pada graf.

2. Urutkan titik-titik pada graf berdasarkan derajatnya (dari derajat terbesar ke derajat terkecil).

3. Gunakan warna pertama untuk mewarnai titik dengan derajat tertinggi.

4. Warnai setiap titik yang tidak bertetangga dengan titik tersebut dengan menggunakan warna yang sama.

5. Ulangi proses pemberian warna (dengan warna berbeda) terhadap 
titik-titik yang belum diberi warna sampai semua titik diwarnai.

\section{HASIL DAN PEMBAHASAN}

Pada penelitian terdahulu, Irwan dan Muliawati (2019) membahas aplikasi pewarnaan graf pada penentuan kamar mahasiswa di asrama Institut Teknologi Sumatera. Pengaturan tersebut dilakukan untuk mengatur agar tidak ada mahasiswa yang berasal dari program studi atau pun daerah asal yang sama dalam satu kamar. Namun demikian, indikator tersebut tidak mendukung efektivitas penggunaan kamar. Hal ini disebabkan oleh kenyataan bahwa lebih dari 50\% mahasiswa calon penghuni asrama berasal dari daerah Lampung.

Berdasarkan fakta di atas, diperlukan indikator pengganti dalam penentuan kamar mahasiswa di asrama Institut Teknologi Sumatera. Pada artikel ini, indikator daerah asal diganti dengan indikator golongan UKT. Selain untuk meningkatkan efektivitas penggunaan kamar di asrama Institut Teknologi Sumatera, pemilihan indikator ini sebagai upaya dalam mendukung kebijakan institusi untuk memupuk rasa saling menghargai dan tolong-menolong di kalangan mahasiswa melalui keberagaman status ekonomi.

Sampel data dari calon mahasiswa penghuni asarama Institut Teknologi Sumatera diberikan sebagai berikut.
Tabel 1. Sampel data dari calon mahasiswa penghuni asrama.

\begin{tabular}{|c|c|c|c|}
\hline No & $\begin{array}{c}\text { Nama } \\
\text { Mahasiswa }\end{array}$ & $\begin{array}{c}\text { Program } \\
\text { Studi }\end{array}$ & $\begin{array}{c}\text { Gol. } \\
\text { UKT }\end{array}$ \\
\hline 1 & Mahasiswa 1 & $\begin{array}{c}\text { Teknik } \\
\text { Informatika }\end{array}$ & 2 \\
\hline 2 & Mahasiswa 2 & $\begin{array}{c}\text { Teknik } \\
\text { Geofisika }\end{array}$ & 4 \\
\hline 3 & Mahasiswa 3 & $\begin{array}{c}\text { Teknik } \\
\text { Lingkungan }\end{array}$ & 1 \\
\hline 4 & Mahasiswa 4 & $\begin{array}{c}\text { Teknik } \\
\text { Elektro }\end{array}$ & 3 \\
\hline 5 & Mahasiswa 5 & $\begin{array}{c}\text { Teknik } \\
\text { Lingkungan }\end{array}$ & 0 \\
\hline 6 & Mahasiswa 6 & $\begin{array}{c}\text { Teknik } \\
\text { Geomatika }\end{array}$ & 5 \\
\hline 7 & Mahasiswa 7 & $\begin{array}{c}\text { Fisika } \\
\text { Matematika }\end{array}$ & 1 \\
\hline 8 & Mahasiswa 8 & Teknik & 0 \\
\hline 9 & Mahasiswa 9 & $\begin{array}{c}\text { Geofisika } \\
\text { Teknik Sipil }\end{array}$ & 1 \\
\hline 10 & Mahasiswa 10 & $\begin{array}{c}\text { Teknik } \\
\text { Geomatika }\end{array}$ & 2 \\
\hline 11 & Mahasiswa 11 & $\begin{array}{c}\text { Teknik } \\
\text { Geofisika }\end{array}$ & 3 \\
\hline 12 & Mahasiswa 12 \\
\hline 13 & Mahasiswa 13 & $\begin{array}{c}\text { Geknik } \\
\text { Geomatika }\end{array}$ & 4 \\
\hline 14 & Mahasiswa 14 & $\begin{array}{c}\text { Teknik } \\
\text { Geologi }\end{array}$ & 0 \\
\hline 15 & Mahasiswa 15 & $\begin{array}{c}\text { Teknik } \\
\text { Geologi }\end{array}$ & 3 \\
\hline
\end{tabular}

Representasi data di atas ke dalam bentuk graf dijelaskan sebagai berikut. Setiap mahasiswa mewakili satu titik pada graf sehingga diperoleh suatu graf $G$ yang terdiri dari 15 titik misalkan $V(G)=\left\{v_{1}, v_{2}, \ldots, v_{15}\right\} . \quad$ Titik $v_{i}$ dikatakan bertetangga dengan titik $v_{j}$ jika mahasiswa $i$ dan mahasiswa $j$ berasal dari program studi atau golongan UKT yang sama. Berdasarkan data tersebut, diperoleh matriks ketetanggaan sebagai berikut. 


$$
A(G)=\left[\begin{array}{lllllllllllllll}
0 & 0 & 0 & 0 & 0 & 0 & 0 & 0 & 0 & 0 & 1 & 0 & 0 & 0 & 0 \\
0 & 0 & 0 & 0 & 0 & 0 & 0 & 0 & 1 & 0 & 0 & 1 & 1 & 0 & 0 \\
0 & 0 & 0 & 0 & 1 & 0 & 1 & 0 & 0 & 1 & 0 & 0 & 0 & 0 & 0 \\
0 & 0 & 0 & 0 & 0 & 0 & 0 & 1 & 0 & 0 & 0 & 1 & 0 & 0 & 1 \\
0 & 0 & 1 & 0 & 0 & 0 & 0 & 0 & 1 & 0 & 0 & 0 & 0 & 1 & 0 \\
0 & 0 & 0 & 0 & 0 & 0 & 0 & 0 & 0 & 0 & 1 & 0 & 1 & 0 & 0 \\
0 & 0 & 1 & 0 & 0 & 0 & 0 & 0 & 0 & 1 & 0 & 0 & 0 & 0 & 0 \\
0 & 0 & 0 & 1 & 0 & 0 & 0 & 0 & 0 & 0 & 0 & 1 & 0 & 0 & 1 \\
0 & 1 & 0 & 0 & 1 & 0 & 0 & 0 & 0 & 0 & 0 & 1 & 0 & 1 & 0 \\
0 & 0 & 1 & 0 & 0 & 0 & 1 & 0 & 0 & 0 & 0 & 0 & 0 & 0 & 0 \\
1 & 0 & 0 & 0 & 0 & 1 & 0 & 0 & 0 & 0 & 0 & 0 & 1 & 0 & 0 \\
0 & 1 & 0 & 1 & 0 & 0 & 0 & 1 & 1 & 0 & 0 & 0 & 0 & 0 & 1 \\
0 & 1 & 0 & 0 & 0 & 1 & 0 & 0 & 0 & 0 & 1 & 0 & 0 & 0 & 0 \\
0 & 0 & 0 & 0 & 1 & 0 & 0 & 0 & 1 & 0 & 0 & 0 & 0 & 0 & 1 \\
0 & 0 & 0 & 1 & 0 & 0 & 0 & 1 & 0 & 0 & 0 & 1 & 0 & 1 & 0
\end{array}\right]
$$

Telah dijelaskan bahwa jumlah dari entri-entri pada baris (kolom) ke- $i$ menyatakan derajat dari titik $v_{i}$. Dengan demikian, diperoleh derajat dari titik-titik pada graf $G$ sebagai berikut.

Tabel 2. Derajat dari setiap titik pada graf.

\begin{tabular}{|c|c|}
\hline Titik & Derajat \\
\hline$v_{1}$ & 1 \\
\hline$v_{2}$ & 3 \\
\hline$v_{3}$ & 3 \\
\hline$v_{4}$ & 3 \\
\hline$v_{5}$ & 3 \\
\hline$v_{6}$ & 2 \\
\hline$v_{7}$ & 2 \\
\hline$v_{8}$ & 3 \\
\hline$v_{9}$ & 4 \\
\hline$v_{10}$ & 2 \\
\hline$v_{11}$ & 3 \\
\hline$v_{12}$ & 5 \\
\hline$v_{13}$ & 3 \\
\hline$v_{14}$ & 3 \\
\hline$v_{15}$ & 4 \\
\hline
\end{tabular}

Selanjutnya, algoritma WelshPowell digunakan untuk memastikan bahwa tidak ada mahasiswa yang berasal dari program studi atau pun golongan UKT yang sama dalam satu kamar. Penerapan algoritma tersebut diawali dengan mengurutkan titik-titik pada graf $G$ berdasarkan derajatnya (dari derajat terbesar ke derajat terkecil). Diperoleh hasil sebagai berikut.

Tabel 3. Urutan titik dari derajat tertinggi dan pewarnaan titik.

\begin{tabular}{|c|c|c|c|}
\hline No & Titik & Derajat & Warna \\
\hline 1 & $v_{12}$ & 5 & 1 \\
\hline 2 & $v_{15}$ & 4 & 2 \\
\hline 3 & $v_{9}$ & 4 & 2 \\
\hline 4 & $v_{14}$ & 3 & 1 \\
\hline 5 & $v_{13}$ & 3 & 1 \\
\hline 6 & $v_{11}$ & 3 & 2 \\
\hline 7 & $v_{8}$ & 3 & 3 \\
\hline 8 & $v_{5}$ & 3 & 3 \\
\hline 9 & $v_{4}$ & 3 & 4 \\
\hline 10 & $v_{3}$ & 3 & 1 \\
\hline 11 & $v_{2}$ & 3 & 3 \\
\hline 12 & $v_{10}$ & 2 & 2 \\
\hline
\end{tabular}




\begin{tabular}{|l|l|l|l|}
\hline 13 & $v_{7}$ & 2 & 3 \\
\hline 14 & $v_{6}$ & 2 & 3 \\
\hline 15 & $v_{1}$ & 1 & 1 \\
\hline
\end{tabular}

Berdasarkan Tabel 3 di atas, dapat disimpulkan bahwa bilangan kromatik dari graf $G$ adalah 4.

\section{KESIMPULAN}

Berdasarkan penjelasan di atas, dapat disimpulkan bahwa hasil yang diperoleh pada artikel ini jelas lebih baik jika dibandingkan dengan hasil yang dikemukakan dalam Irwan dan Muliawati (2019). Dalam artikel tersebut diperoleh bahwa bahwa bilangan kromatik dari graf $G$ adalah 8. Dengan asumsi bahwa kapasitas maksimal adalah 4 orang per kamar, dibutuhkan 9 kamar untuk menempatkan 15 mahasiswa tersebut sehingga tidak ada mahasiswa yang berasal dari program studi atau pun daerah asal yang sama dalam satu kamar.Sedangkan dalam artikel ini, diperoleh bahwa bilangan kromatik dari graf $G$ adalah 4. Dengan asumsi yang sama bahwa kapasitas maksimal adalah 4 orang per kamar, hanya dibutuhkan 6 kamar untuk menempatkan 15 mahasiswa tersebut sehingga tidak ada mahasiswa yang berasal dari program studi atau pun golongan UKT yang sama dalam satu kamar.

\section{Ucapan Terima Kasih}

Penelitian ini didanai oleh Hibah Mandiri Institut Teknologi Sumatera No. 134bl/IT9.C1/PP/2018.

\section{DAFTAR PUSTAKA}

Biggs, N. (1996). Algebraic Graph Theory $2^{\text {nd }}$ edition. New York: Cambridge University.

Bincy, A. K. dan Pressitha, B. J. (2017). Graph coloring and its real time applications an overview. International Journal of Mathematics and its applications. Vol. 5. 845-849.

Diestel, R.(2005).Graph theory $3^{\text {rd }}$ edition. New York: Springer-Verlag Heidelberg.

Gupta, P. and Sikhwal, O. (2014). A study of vertex-edge coloring techniques with application. International Journal of Core Engineering \& Management. Vol. 1. 27-32.

Irwan, S. E. and Muliawati, T.(2019).A graph theory approach to the dormitory room placement problem.Journal of Science and Applicative Technology: ICOSITER Special Edition. Vol. 2 No. 1. 111118.

Marx, D. (2004). Graph colouring problems and their applications in scheduling. Periodica Polytechnica Ser. El. Eng. Vol. 48 No. 1. 11-16.

Tosuni, B. (2015). Graph theory in computer science - an overview. International Journal of Academic Research and Reflection. Vol. 3 No. 4. 55-62. 